\title{
Medical Image of the Week: Accessory Cardiac Bronchus
}
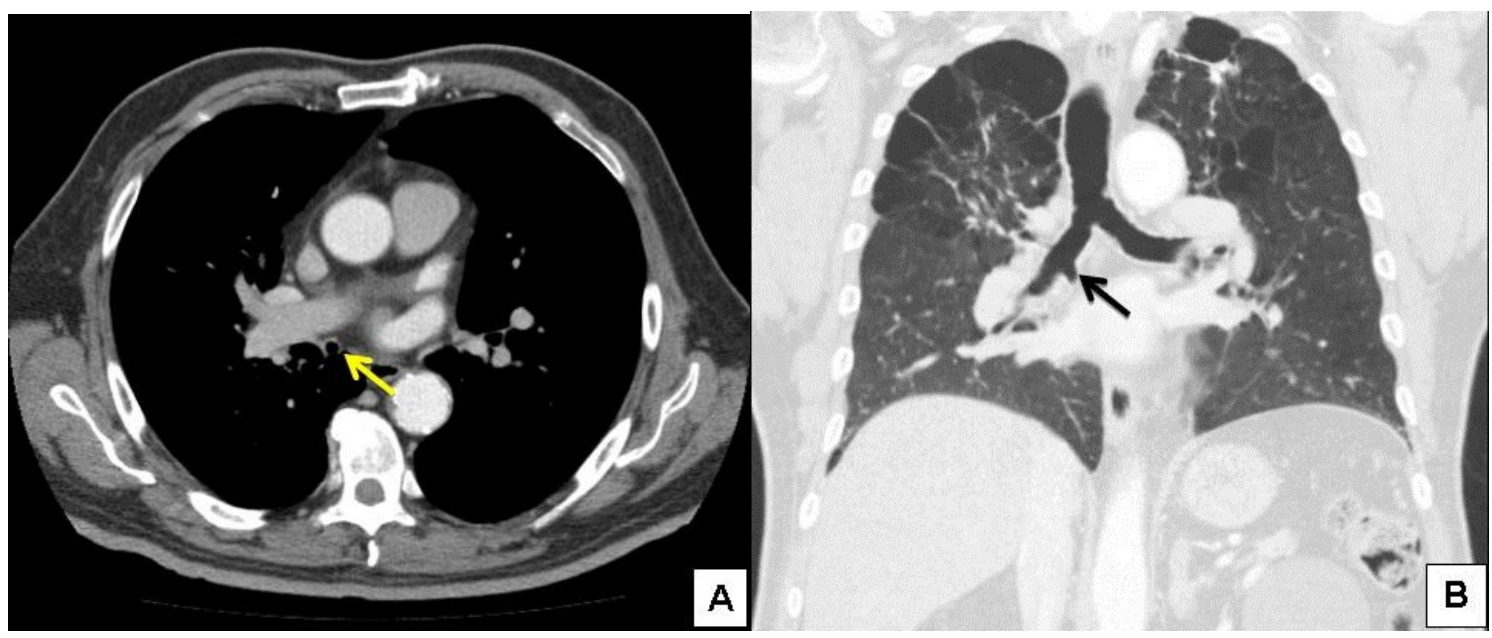

Figure 1. Axial (Panel A) and Coronal (Panel B) CT Chest demonstrate an accessory cardiac bronchus that can be seen in the axial and coronal views (arrows) arising from the bronchus intermedius.

A 77-year-old man with a 120 pack-year smoking history was found to have incidental rudimentary bronchus arising from the medial wall of the bronchus intermedius on thoracic CT obtained for lung nodule evaluation.

A congenital tracheobronchial anomaly called a cardiac bronchus was first described in 1946 by Brock and is thought to develop in the $6^{\text {th }}$ week of gestation. The incidence of a cardiac bronchus is reported as $0.07-0.5 \%$ and is most commonly seen arising directly opposite the right upper lobe orifice. The average diameter is $8.7 \mathrm{~mm}$ and the average length is $12 \mathrm{~mm}$ advancing in a caudal direction towards the pericardium. Cardiac bronchi are lined by normal bronchial mucosa and have cartilage, which distinguish them from acquired diverticula. Most end abruptly but some do develop small bronchioles and bronchiolar parenchymal tissue. Accessory cardiac bronchi are usually asymptomatic and discovered incidentally as in this case, but can be associated with cough, hemoptysis, and recurrent infections. Pulmonologists should be aware of this congenital accessory bronchus in order to properly evaluate patients during diagnostic bronchoscopy.

Bhupinder Natt MD, Veronica Arteaga MD, Janet Campion MD University of Arizona Medical Center, Tucson AZ.

\section{Reference}

Desir A, Ghaye B. Congenital anomalities of intrathoracic airways. Radiologic Clinics of North America. 2009; 47(2); 203-225. [CrossRef] [PubMed] 